\title{
DE INVLOED VAN HET NEDERLANDS OP DE SYNTAXIS EN DE WOORDENSCHAT VAN HET JAPANS
}

\author{
CHRISTOPHER JOBY
}

\begin{abstract}
The influence of Dutch on Japanese syntax and lexicon

The Netherlands traded extensively with Japan between 1609 and 1854 . During this period the Dutch exported not only goods into Japan, but also books which they sold to the Japanese. In due course, Japanese interpreters and intellectuals began to translate these books into Japanese and by about 1850 they had translated around 1,000 Dutch books. This article examines the influence of the Dutch language on Japanese, resulting from the translation of these books and from language contact. This influence was twofold, syntactic and lexical. As for the former, in order to render Dutch texts into Japanese, translators introduced several features including a new relative pronoun, tokoro no, and a new compound word, ni yotte, in order to translate the Dutch word door' ('by') in passive sentences. As concerns the latter, Japanese translators used a number of approaches in order to render new objects and ideas in Japanese. They occasionally created a new compound word from the constituent parts of a Dutch compound word. In other cases, they formed new compounds from Dutch and Japanese words and morphemes, or transcribed Dutch words in the Japanese katakana syllabary. This final approach was also used for loanwords which Japanese adopted as a result of language contact with Dutch, such as, for example, in the case of $k o k k u$ (コック) from the Dutch kok.
\end{abstract}

Key words: Japanese; language contact; translation; Dutch loanwords; grammatical influence

\section{Inleiding}

Tussen 1609 en 1854 dreef Nederland veel handel met Japan, tot 1799 onder de vlag van de VOC en daarna onder die van de Nederlandse staat. In die periode voeren er meer dan 800 Nederlandse schepen naar het eiland Kyushu in het westen van Japan. Daar richtten de Nederlanders handelsposten op, tussen 1609 en 1641 in Hirado en tussen 1641 en 1854 op Dejima, een kunstmatig eilandje in de Baai van Nagasaki. Naar schatting sprak de helft van de mensen aan boord van deze schepen Nederlands als moedertaal. Het waren niet alleen zeelui maar ook hoogopgeleide administrateurs die de Nederlandse 
handelsposten zouden leiden, en chirurgen, artsen en boekhouders. In het begin spraken de Japanse tolken die de Nederlanders begeleidden vooral Portugees, omdat er al sinds het midden van de zestiende eeuw Portugezen in Japan waren geweest. Maar geleidelijk aan begonnen deze tolken Nederlands te leren en vanaf het begin van de achttiende eeuw konden de Nederlanders hun moedertaal gebruiken om met hulp van de tolken met de Japanse administrateurs, machthebbers en kooplui te communiceren.

In deze periode importeerden Nederlanders niet alleen goederen, maar ook veel boeken, met name Nederlandstalige. In de loop van de achttiende en de negentiende eeuw werden duizenden boeken over verschillende wetenschappelijke onderwerpen geïmporteerd en ongeveer 1000 daarvan vanuit het Nederlands naar het Japans vertaald (Clements 2015). Deze boeken bevorderden de Japanse kennis op een aantal vakgebieden, zoals de geneeskunde, sterrenkunde en plantkunde, en daardoor oefenden ze een grote invloed uit op de Japanse samenleving.

Deze bijdrage neemt de invloed onder de loep van het Nederlands op het Japans die destijds is ontstaan door taalcontact en de vertaling van deze boeken. Deze invloed kan bekeken worden op tweeërlei gebied - de zinsbouw en de woordenschat. Om het Nederlands goed in het Japans te kunnen verwoorden moesten Japanse vertalers onder andere een betrekkelijk voornaamwoord tokoro no introduceren en een samenstelling ni yotte creëren om het Nederlandse woord door in passieve zinnen te kunnen vertalen.

Wat de woordenschat betreft, moesten de Japanse vertalers een aantal methodes gebruiken om nieuwe voorwerpen en ideeën in het Japans te verwoorden. Soms creëerden ze een nieuwe samenstelling die op de losse delen van Nederlandse samenstellingen gebaseerd was, soms vormden ze nieuwe samenstellingen uit Nederlandse en Japanse woorden en morfemen en soms gaven ze Nederlandse woorden in het hoekige lettergreepschrift katakana weer. Dit laatste gold ook voor leenwoorden die Japanners overnamen naar aanleiding van het taalcontact met het Nederlands, bijvoorbeeld bìru (ビール) van het Nederlands bier.

\section{De invloed van het Nederlands op de Japanse grammatica}

Ten eerste zal ik ingaan op de invloed van het Nederlands op de Japanse grammatica, met name de syntaxis. Omdat de syntaxis van het Nederlands en het Japans zo verschillend zijn, bedachten Japanse vertalers nieuwe zinsdelen en toevoegsels en namen die in gebruik om het Nederlands zo goed mogelijk in het Japans te kunnen verwoorden.

\subsection{Tokoro no}

Het eerste te noemen zinsdeel is tokoro no (ところの), een betrekkelijk voornaamwoord dat in adnominale bijzinnen voorkomt. Het bestaat uit twee delen, tokoro, dat 'plaats' betekent en het partikel no. In het Oud-Japans (tot circa 800) bestonden er geen betrekkelijke voornaamwoorden in betrekkelijke bijzinnen. Volgens Earns hebben Japanse vertalers van Nederlandse teksten dit zinsdeel overgenomen van het kanbun (漢文) (Earns 1993, 1996). Dat is een vorm van klassiek Chinees of wényánwén (文言文) dat 
door hoogopgeleide Japanners werd gebruikt. In het kanbun is tokoro no een betrekkelijk voornaamwoord dat altijd naar een nominaal hoofd verwijst als lijdend voorwerp van een bijzin. We vinden een eenvoudig voorbeeld onder (1).
(1) Hossuru tokoro no mono Wil dat ding
"Het ding dat men wil hebben"

Het betrekkelijk voornaamwoord dat is het lijdend voorwerp van de bijzin. Geleidelijk aan begon tokoro no tevens andere functies over te nemen. Het eerste gebruik daarvan is te dateren in 1730, namelijk in een tekst over sterrenkunde (Earns 1996). Zie (2). ${ }^{1}$

$\begin{array}{llll}\text { (2) Kōmōjin } & \text { mochi wataru } & \text { tokoro no } & \text { seizu } \\ \text { Nederlanders } & \text { binnenbrachten } & \text { die } & \text { sterrenkaart }\end{array}$

"De sterrenkaart die de Nederlanders binnenbrachten"

Dit is eigenlijk heel vroeg in de geschiedenis van het vertalen vanuit het Nederlands naar het Japans aangezien de eerste pogingen daartoe pas tegen het einde van de zeventiende eeuw werden gemaakt. In 1815 geeft de vertaler van Oranda gohō kai (和蘭語法 解) ('Interpretatie van Nederlandse grammatica') zinnen met tokoro no, waar het betrekkelijk voornaamwoord naar een nominaal hoofd verwijst dat het onderwerp, en niet het lijdend voorwerp, van een bijzin is. Zie (3). ${ }^{2}$

\begin{tabular}{|c|c|c|c|c|}
\hline $\begin{array}{l}\text { Kore o } \\
\text { Dit (LV) }\end{array}$ & $\begin{array}{l}\text { setsumeisuru } \\
\text { uitlegt }\end{array}$ & $\begin{array}{ll}\text { tokoro no } & \text { bunpō } \\
\text { die } & \text { grammatica }\end{array}$ & $\begin{array}{l}\text { o } \\
(\mathrm{LV})\end{array}$ & $\begin{array}{l}\text { iu } \\
\text { verwijst }\end{array}$ \\
\hline
\end{tabular}

Hier verwijst tokoro no ('die') naar grammatica en is dus onderwerp van de bijzin. Tot het einde van de Tokugawa- (of Edo-)periode (1603-1868) werd het gebruik van tokoro no beperkt tot Japanse vertalingen van Nederlandse teksten. Pas in de daaropvolgende Meiji-periode, vanaf 1868, werd het op een uitgebreidere manier in het Japans gebruikt (Martin 1975).

\subsection{Ni yotte}

Een andere manier waarop de Japanse grammatica werd aangepast als gevolg van het vertalen vanuit het Nederlands is het gebruik van het samengestelde achtervoegsel $n i$ yotte (によって) in passieve zinnen. Vóór de komst van de Nederlanders was het achtervoegsel $n i$ に reeds in gebruik in het Japans om de agens in passieve zinnen aan te duiden. Tegen het einde van de Tokugawa-periode hebben de Japanse vertalers van Nederlandse

1 Earns vermeldt de naam van de tekst als Dairyaku tenmon meimokusho, maar momenteel kan ik deze tekst niet terugvinden. Kōmōjin betekent letterlijk 'roodharigen'. De Japanners beschouwden de Nederlanders dus als roodharig.

2 Clements (2015) geeft het jaar 1811 voor de publicatie van Oranda gohō kai.

$3 \mathrm{LV}=$ lijdend voorwerp. 
teksten de nieuwe samenstelling ni yotte によって gecreëerd om het Nederlandse woord door aan te duiden. ${ }^{4}$ Kinsui beweert dat vertalers door aanvankelijk algemeen door middel van ni yotte vertaalden en dat deze uitdrukking vervolgens geleidelijk ook gebruikt werd voor door in passieve zinnen (1997: 772).

Volgens Kinsui staat het eerste voorbeeld van een passieve zin in het Japans waarin $n i$ yotte wordt gebruikt, in een Japanse vertaling van de tweede editie van Grammatica of Nederduitsche Spraakkunst van Matthijs Siegenbeek, die in 1822 in Leiden werd gedrukt. ${ }^{5}$ De Japanse vertaling die in 1856 in Tokyo werd uitgegeven, heette Sōyaku Garammachika (挿訳俄蘭磨智科). Voor de desbetreffende passieve zin, zie (4)

(4) Er zijn echter eenige algemeene regelen en waarnemingen hieromtrent door kundige Taalbeoefenaars voorgesteld.

Door kundige Taalbeoefenaars voorgesteld werd in het Japans weergegeven als in (5).

(5)

$\begin{array}{llll}\text { takuminaru } & \text { gogakusha } & \text { ni yotte } & \text { sadame-rare-taru } \\ \text { kundige } & \text { taalbeoefenaars } & \text { door } & \text { voorgesteld }\end{array}$

In deze bijdrage blijft de hele geschiedenis van de ontwikkeling van het gebruik van $n i$ yotte buiten beschouwing. Wat echter moet worden vermeld is dat hoewel het Nederlands na het begin van de Meiji-periode minder belangrijk werd in Japan, ni yotte in gebruik bleef om het agens in passieve zinnen in andere Europese talen in het Japans weer te geven en geleidelijk aan in het alledaagse Japans. In feite is het niet gemakkelijk om vast te stellen wanneer men in het hedendaagse Japans ni of ni yotte zou moeten gebruiken om het agens in passieve zinnen aan de duiden. Het blijkt echter dat ni yotte vooral wordt gebruikt in zinnen waar het hoofdwerkwoord met 'vormen' of 'creëren' te maken heeft. Vergelijk het gebruik van $n i$ in (6) met dat van ni yotte in (7) en (8).

(6) Sensei wan ni shitsumono o sereta.

Leraar betreffende John door vraag (LV) werd-gesteld

"De leraar werd een vraag (door John) gesteld" (Makino en Tsutsui 2009)6

(7) Ibento

Evenementen door

ga umareru.

“De solidariteit wordt gecreëerd door [het opvoeren van] evenementen”(Kaiser 2013) ${ }^{7}$

(8) Kono e wa pikaso ni yotte kakareta.

Dit beeld betreffende Picasso door werd-geschilderd.

"Dit beeld werd door Picasso geschilderd" (Makino en Tsutsui 2009)

4 Ni yotte bestaat uit twee delen, dat wil zeggen: het achterzetsel ni に en yotte (よって). Yotte (よって) is de conjunctieve of -te ( $)$ vorm van het werkwoord yoru dat een aantal betekenissen heeft, waaronder 'worden veroorzaakt door' (Kinsui 1997).

5 De Grammatica werd tevens in Deventer en Groningen gedrukt.

6 Het Japanse partikel wa duidt het thema van de zin aan. Verder wijzen we erop dat het Japans geen lidwoorden kent.

$7 \mathrm{O}=$ onderwerp. 


\subsection{Andere invloeden van het Nederlands op de Japanse grammatica}

Drie andere manieren waarop de Japanse grammatica werd aangepast onder de invloed van het vertalen vanuit het Nederlands, zijn het gebruik van het pseudo-koppelwerkwoord de aru aan het zinseinde; de ontwikkeling die leidde tot het gebruik van abstracte termen als onderwerp van een zin; en het toenemende gebruik van pseudo-voornaamwoorden.

Zoals in het geval van tokoro no en ni yotte was het gebruik van het pseudo-koppelwerkwoord de aru (である) tot het einde van de Tokugawa-periode vrijwel beperkt tot het vertalen vanuit het Nederlands naar het Japans. ${ }^{8}$ Eigenlijk komt het in de Tokugawa-periode niet zo vaak voor. Een voorbeeld uit die periode is te vinden in het Doyaku of Zūfu-haruma (ドゥーフ・ハルマ), een Nederlands-Japans woordenboek waarvan de eerste versie in 1816 onder leiding van het opperhoofd op Dejima Hendrick Doeff werd voltooid. Zie (9).

(9) Kano hito wa $\quad$ mada gakumon-ni
Die persoon betreffende nog wetenschappen-in

$\mathrm{Na}$ het einde van de Tokugawa-periode werd de aru op een uitgebreidere manier gebruikt (Earns 1993). Men vindt deze en de tweede ontwikkeling, dat wil zeggen het gebruik van abstracte termen als onderwerp, in een andere zin in het Dōyaku-haruma woordenboek: rokujūyon-no heihōkon-wa hachi de aru, wat de vierkantswortel van vierenzestig is acht of letterlijk vierenzestig van vierkantswortel acht is betekent (Vos 2014). Wat de tweede ontwikkeling betreft, wijzen we erop dat abstracte termen als heihōkon ('vierkantswortel') onmogelijk onderwerp van de Japanse zin konden zijn voordat het Nederlands haar invloed heeft doen gelden via de vertalingen naar het Japans.

Ten slotte beweert de Nederlandse japanoloog Vos (2014) dat het frequente gebruik van pseudo-voornaamwoorden zoals kare (彼) en kanojo (彼女) te danken is aan de interactie tussen het Nederlands en het Japans. Nu betekent kare hij, maar oorspronkelijk werd het als aanwijzend voornaamwoord gebruikt, terwijl kanojo, dat nu $z i j$ betekent, letterlijk als die vrouw kan worden vertaald. Hiervóór werd minder gebruik gemaakt van dergelijke voornaamwoorden, omdat Japanners het onderwerp van een werkwoord uit de context konden afleiden (Vos 2014).

Kortom, men kan stellen dat een van de gevolgen van het taalcontact tussen het Nederlands en het Japans een aantal aanpassingen van de Japanse grammatica is die tot op heden nog in gebruik zijn.

8 Volgens Vos (2014) komt dit pseudo-koppelwerkwoord af en toe voor tegen het einde van de Muromachiperiode (室町時代) (1336-1573), maar daarna zeer zelden tot de opkomst van de Japanse vertalingen uit het Nederlands. 


\section{De invloed van het Nederlands op de Japanse woordenschat}

Het tweede gevolg van het taalcontact dat hier besproken zal worden, is de invloed van het Nederlands op de Japanse woordenschat. In sommige gevallen gaat het om Nederlandse woorden die door Japanstaligen zijn overgenomen, in andere gevallen hebben Japanners nieuwe samenstellingen gecreëerd. ${ }^{9}$ Wat hier wordt besproken, is in grote mate gebaseerd op secondaire bronnen, vooral op het werk van Vos (2014).

Vandaag de dag bevat de Japanse woordenschat zo'n 160 leenwoorden uit het Nederlands (Vos 2014). Vaak is het moeilijk vast te stellen wanneer deze woorden door het Japans zijn overgenomen. Vos beweert bijvoorbeeld dat al in 1613 het Nederlandse leenwoord kok in een Japanstalig document verscheen. In het Japans wordt dit uitgesproken als kokku (コック), omdat alle Japanse woorden op een klinker of een - $n$ moeten eindigen. ${ }^{10}$ Maar het is de vraag of dit feitelijk zo is. Een probleem met Vos' bewering is dat hij geen primaire bron vermeldt om zijn claim te rechtvaardigen. Een ander probleem is dat dit heel vroeg lijkt te zijn, aangezien de Nederlanders pas in 1609 handel met Japan begonnen te drijven.

Soms leidt het niet vermelden van primaire bronnen naar een verschil van datum in de wetenschappelijke literatuur. Irwin (2011) beweert bijvoorbeeld dat het Nederlandse

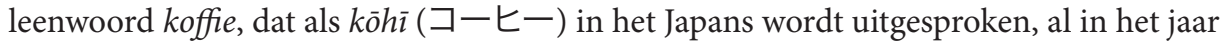
1615 in Japanse bronnen verscheen. Daartegenover beweert Vos dat kōhi pas in 1797 voor het eerst in Japanse bronnen verscheen (Irwin 2011, Vos 2014). Geen van beiden vermeldt een bron.

Niettemin is het wel zo dat het Japans een vrij groot aantal leenwoorden uit het Nederlands heeft overgenomen. Om aan te duiden dat een Japans woord afkomstig is uit een andere taal, met uitzondering van het Chinees, wordt het normaal gesproken in het katakana-lettergreepschrift weergegeven. Dit verklaart waarom de meeste Nederlandse leenwoorden in het Japans in dat schrift staan genoteerd. ${ }^{11}$ Hoewel we niet zeker weten wanneer kokku en $k \bar{o} h \bar{\imath}$ voor het eerst in het Japans werden gebruikt, is het wel zo dat ze tot op de dag van vandaag in het standaard Japans worden gebruikt. Enkele andere leenwoorden zijn biru van het Nederlandse woord bier, koruku (コルク) en kiru$k u$ (キルク) van het Nederlandse woord kurk, en buriki (ブリキ) van het Nederlandse woord blik (Vos 2014).

In sommige gevallen is een leenwoord wel overgenomen en ingeburgerd in een Japans dialect, maar niet in het Standaardjapans terechtgekomen. Een voorbeeld daarvan is dontaku (ドンタク) (Vos 2014). Dit woord, dat rustdag betekent, komt van het Nederlandse woord zondag. Het wordt nog steeds gebruikt in varianten van het Japans op Kyushu, zoals die van de stad Hakata, waar men de term Hakatadontaku of 'Hakata dontaku festival' vindt. ${ }^{12}$

9 Voor een kort overzicht van Nederlandse leenwoorden in het Japans, zie Tanaka-Van Daalen (2000).

10 De - $n$ ( $ん$ (hiragana) of ン (katakana)) wordt vaak maar niet altijd als [n] uitgesproken.

11 Kanji, hiragana en romaji zijn andere Japanse schriften.

12 Hakatadontaku wordt in kanji en een ander lettergreepschrift, hiragana, geschreven (博多どんたく). Dit betekent dat het hoogstwaarschijnlijk niet als een leenwoord wordt beschouwd. Dontaku wordt in andere delen van Japan gebruikt, maar met andere betekenissen. Bijvoorbeeld in Hiroshima, in het Westen van Honshu, bekekent het 'dom' (Vos 2014). 
Het overnemen van deze en andere Nederlandse woorden en het weergeven daarvan in katakana is echter niet de enige manier waarop het Nederlands de Japanse woordenschat heeft beïnvloed. Om nieuwe voorwerpen en ideeën in het Japans te verwoorden creëerden de Japanse vertalers en andere Japanstaligen nieuwe samenstellingen die gebaseerd waren op de losse onderdelen van Nederlandse samenstellingen. Deze nieuwe samenstellingen gaven ze weer in kanji (漢字)-karakters of ideogrammen van Chinese oorsprong. ${ }^{13}$

$\mathrm{Al}$ in de negentiende eeuw werden dergelijke Japanse samenstellingen gecreëerd om Nederlandse grammaticale termen weer te geven. Rond 1800 verscheen bijvoorbeeld daimeishi (代名詞) in het Japans. Dit is een bijna letterlijke vertaling van de Nederlandse term voornaamwoord: dai (代) kan duidt op betekenen, mei (名) betekent naam en shi (詞) betekent woord. Een tweede voorbeeld is joshi (助詞) dat in 1856 voor het eerst werd gebruikt. Dat komt van het Japans jo (助) hulp en shi (詞) woord en was een vertaling van de Nederlandse term hulpwerkwoord. In de loop van de tijd is de betekenis van joshi veranderd, en nu duidt het achterzetsel aan (Miller 1967).

Een ander soort leenwoord is de hybridevorm waarbij het ene deel van Nederlandse afkomst is en het andere van Japanse afkomst. Vos (2014) noemt 32 van dit soort leenwoorden. Een interessant voorbeeld daarvan is Raiden-bin (ライデン瓶) dat Leidse fles betekent. Het eerste deel dat in katakana wordt geschreven, is een verjapanste weergave van het toponiem Leiden en het tweede deel bin is het Japanse woord van Chinese of Chinees-Japanse afkomst voor 'fles' (Vos 2014). Een ander voorbeeld is het dialectische woord handon (半ドン), dat halfrustdag betekent. Het eerste deel, han (kanji 半), is het Chinees-Japans woord voor half en het tweede deel don (katakanaドン) is de eerste lettergreep van het net besproken dontaku. ${ }^{14}$

Het eerste deel van een antal van zulke leenwoorden is oranda. Dit is eigenlijk een Portugese versie van het toponiem Holland, dat door Japanstaligen werd overgenomen en verjapanst. Het komt in de naam van een aantal soorten fruit of groenten voor om aan te duiden dat ze van Nederlandse of 'buitenlandse' afkomst zijn, bijvoorbeeld oranda-ichigo (オランダいちご) (aardbei, Latijn: Fragaria x ananassa) (Vos 2014). ${ }^{15}$ Oranda wordt ook als voorvoegsel gebruikt bij een aantal toponiemen in Nagasaki en andere steden op Kyushu. Dit ziet men terug in het toponiem Oranda-zaka (オランダ坂) of Hollandse Helling, die zich in Nagasaki bevindt.

Andere toponiemen in het Japans zijn of deels of geheel van Nederlandse afkomst. Het Japanse woord voor Duitsland is doitsu (ドイツ), afkomstig van het Nederlandse woord Duits (Vos 2014). In Tokyo vindt men ten slotte een voorvoegsel van Nederlandse afkomst dat in een aantal toponiemen voorkomt. Een van de eerste Nederlanders in Japan was Jan Joosten van Lodensteyn (1556-1623). In 1600 kwamen hij en zijn schipgenoten aan boord van de Liefde in Japan aan. Ze mochten Japan echter niet verlaten. In de loop der tijd verhuisde Jan Joosten naar Tokyo en werd koopman en eveneens adviseur van de

13 Één kanji komt bijna altijd overeen met één morfeem.

14 Handon kan ook in kanji en hiragana worden geschreven (半どん). Normaal gesproken wordt hiraga$n a$ niet gebruikt om woorden of morfemen van Westerse afkomst weer te geven.

15 Hier wordt het woord in katakana en hiragana geschreven, maar het kan ook in katakana en kanji worden geschreven: (オランダ苺). Zie www.tangorin.com. Geraadpleegd op 11 april 2018. Zie ook het lemma Oranda op deze site voor andere voorbeelden van zulke samenstellingen. 
shogun. De buurt in Tokyo waar hij woonde, kreeg een verjapanste versie van zijn naam, Yaesu (八重洲). ${ }^{16}$ Dit ziet men vandaag nog terug in samengestelde toponiemen in en rond het Centraal Station dat zich in die buurt in Tokyo bevindt, bijvoorbeeld, Yaesu kitaguchi (八重洲 北口), i.e. Yaesu Noordingang.

\subsection{Nederlandse leenwoorden in het Koreaans en het Taiwanees}

Vanwege de historische betrekkingen tussen Japan en Korea is een aantal Nederlandse leenwoorden in het Japans overgenomen door het Koreaans. Vos (2014) vermeldt er 27, waarvan een interessant voorbeeld het Koreaanse woord mesu (메스) is, dat scalpel betekent. ${ }^{17}$ Dit is afkomstig van het Japanse woord mesu (メス), dat op zijn beurt van het Nederlandse woord mes komt. Een ander voorbeeld is kabang (가방) (zak) (Vos 2014). ${ }^{18}$ Dit komt van het Japanse woord kaban, een Nederlands leenwoord afkomstig van het verouderde Nederlandse woord kabas, dat mandje of korfje betekende (Woordenboek der Nederlandsche Taal).

Als gevolg van de Japanse bezetting van Taiwan in de periode 1890-1945 werd tevens een aantal Japanse leenwoorden overgenomen door het Taiwanees (臺灣閩南語), een variant van het Chinees. Een van deze leenwoorden is biru, dat, zoals hierboven vermeld, afkomstig is van het Nederlandse woord bier. In Standaardchinees duidt pijiŭ (啤酒) bier aan.

\section{Conclusie}

Samenvattend kan gesteld worden dat wat de grammatica betreft het duidelijk is dat het vertalen vanuit het Nederlands naar het Japans deze taal op een aantal manieren heeft beïnvloed. Het meest interessante is dat, hoewel sommige zinsdelen en toevoegsels zoals tokoro no en ni yotte in eerste instantie alleen door vertalers werden gebruikt, deze na het einde van de Tokugawa-periode ook door andere Japanstaligen werden gehanteerd en tot op heden intrinsieke delen van de Japanse zinsbouw vormen.

Wat de leenwoorden betreft, is het duidelijk dat er door taalcontact tussen het Nederlands en het Japans veel Nederlandse leenwoorden in het Japans in gebruik zijn. Aan de ene kant maken sommige leenwoorden deel uit van de woordenschat van de standaardtaal, maar aan de andere kant zijn sommige leenwoorden alleen in dialecten terug te vinden. Het feit dat Irwin (2011) en Vos (2014) hun primaire bronnen niet vermelden, betekent dat we er vooralsnog niet zeker van kunnen zijn wanneer Japanstaligen Nederlandse leenwoorden voor het eerst zijn gaan gebruiken. Overigens is er tot nu toe weinig geschreven over de inburgering van Nederlandse leenwoorden in het Japans. Er is dus nog enig onderzoek over dit onderwerp te doen.

16 Yaesu komt van Yayosu, een verjapanste versie van Jan Joosten.

17 Ho-Min Sohn (1999) telt 65 Nederlandse leenwoorden in het Koreaans.

18 Het Japanse woord kaban wordt met de kanji (鞄) geschreven. 


\title{
BIBLIOGRAFIE
}

CLEMENTS, REBEKAH (2015). A Cultural History of Translation in Early Modern Japan. Cambridge: CUP.

EARNS, FUMIKO (1996). "Dutch Influence on the Japanese language at the syntactic level", in: Asian Culture 24.1, 64-71.

EARNS, FUMIKO (1993). Language Adaptation: European language influence on Japanese syntax. Ann Arbor, MI: UMI.

IRWIN, MARK (2011). Loanwords in Japanese. Amsterdam: John Benjamins.

KAISER, STEFAN e.a. (2013). Japanese: A Comprehensive Grammar. Tweede editie. Londen: Routledge. KINSUI, SATOSHI (1997). "The Influence of Translation on the Historical Development of the Japanese Passive Construction", in: Journal of Pragmatics, 28, 6, 759-779.

MAKINO SEIICHI \& MICHIO TSUTSUI (2009). A Dictionary of Basic Japanese Grammar. Tokyo: The Japan Times.

MARTIN, SAMUEL (1975). A Reference Grammar of Japanese. Londen: Yale University Press.

MILLER, ROY (1967). The Japanese Language. Londen: University of Chicago Press.

SOHN, HO-MIN (1999). The Korean Language. Cambridge: CUP.

TANAKA-VAN DAALEN, ISABEL (2000). "Dutch Words and Expressions in Japanese", in: Leonard Blussé e.a. (red.), Bridging the Divide: 400 Years The Netherlands-Japan. Leiden: Hotei Publishing, 129.

VOS, FRITS (2014). "Dutch Influences on the Japanese Language (With an Appendix on Dutch Words in Korean)", East Asian History 39, 153-180.

\section{VLIV NIZOZEMŠTINY NA JAPONSKOU SYNTAX A LEXIKUM}

Mezi lety 1609 a 1854 obchodovalo Nizozemsko intenzivně s Japonskem. Během tohoto období dováželi Nizozemci do Japonska nejen zboží, ale prodávali Japoncům i knihy. Japonští tlumočníci a intelektuálové začali tyto knihy překládat do japonštiny a kolem roku 1850 bylo přeloženo již kolem tisíce nizozemských knih. Př́spěvek zkoumá vliv nizozemského jazyka na japonštinu, který vyplývá z překladu těchto knih a z jazykového kontaktu. Vliv byl dvojí, syntaktický a lexikální. Aby překladatelé mohli překládat nizozemské texty do japonštiny, museli zavést několik neologismů, včetně nového relativního zájmena, tokoro no, či nové složeniny ni jotte, jež v pasivních větách supluje nizozemskou předložku door („skrze“). To je dokladem syntaktického vlivu. Pokud jde o lexikální vlivy, používali překladatelé k uvedení nových objektů a pojmů do japonštiny řadu př́ístupů. Někdy vytvořili novou složeninu ze složek nizozemského složeného slova. $V$ jiných prrípadech vytvořili nové složeniny z nizozemských a japonských slov a morfémů, nebo přepisovali nizozemská slova do japonské katakana syllabary. Tento př́stup byl aplikován na výpůjčky, které Japonci přijali v důsledku jazykového kontaktu s nizozemštinou, jako např́klad v př́ípadě slova kokku (コック) z nizozemského kok (kuchař).

\author{
Christopher Joby \\ Uniwersytet im. Adama Mickiewicza \\ E-mail: christopherjoby@gmail.com
}

